\title{
Impact of training programs on work related variables
}

\author{
B.L Galhena ${ }^{1 *}$, and H.L.A. Mihirani ${ }^{1}$ \\ ${ }^{1}$ Faculty of Management \& Finanace \\ University of Ruhuna
}

\begin{abstract}
Rapidly and ever-changing work environment often creates the enormous challenges for any kind of organizations for ensuring their survival with the competitive business arena. In order to gain Sustainable competitive advantage over the rivalry among their competitive counterparts many organization strive for differentiating form others in terms of various organizational attributes. Though Financial, technological, physical and innovation resources are playing key role in achieving sustainable competitive advantage, the human resources in essence contribute in a great deal with no doubt. In order for developing valuable, rare, inimitable and organizational human capital internally, organizations tend to design and implement continuous training and development program for the employees. Particularly, it has become a severe problem in Sri Lankan business context, how to offer effective trainings for the employees to improve their productivity, performance and job satisfaction. Many organizations often did not achieve the training goals and objective though the extensive amounts of cost is invested on it. In order to search these circumstances, the survey was conducted through the sample which consisted of 110 employees in four production sections at Naturub Accessories (Pvt) Ltd, Sri Lanka. Across all four main variables tested namely job satisfaction, turnover, and productivity and performance researcher found that significance correlation between the variables. Moreover, research found that job satisfaction, productivity and turnover were positively associated while turnover was negatively linked with training program participation.
\end{abstract}

Keywords: Training \& Developments programs, Job Satisfaction, performance, turn over

\section{Introduction}

Rapidly and ever-changing work environment often creates the enormous challenges for any kind of organizations for ensuring their survival with the competitive business arena. In order to gain competitive advantage over the rivalry among their competitive counterparts many organization strive for differentiating form others in terms of various organizational attributes. Resources are the most critical weapon for which every organization seeking for in this contest. Though financial, technological, physical and innovation resources are playing key role in achieving sustainable competitive advantage, the human resources in essence contribute in a great deal with no doubt. In order for developing valuable, rare, inimitable and organizational human capital internally, organizations tend to design and implement continuous training and development program for the employees.

\footnotetext{
*Corresponding author: blgalhena2@gmail.com
}

Training and development which refers any attempt to improve employee performance on a currently held job or one related to it through learning opportunities designed to help employees' growth. A successful training in deed depends on a systematic approach involving a careful needs assessment, solid program design and thorough evaluation of results. The implication of training and development program basically twofold: individual and organizational. On one hand effective training programs may lead to enhance employee performance in current job (Cascio, 2003), job satisfaction, (Gomez et al, 1998) role clarity while minimize employee turnover, (Bohlander \& Snell, 2007). Role ambiguity and job stress. On the other hand, organization productivity, attainment of short and long term organizational goals and objectives will obviously be ensured. In addition, it may cause to inculcate positive employee attitudes among the well-trained work force by giving better knowledge over the problem solving which arising in the working environment (Dessler, 2003) though huge investments are employed on training and development programs, every program however, 
will not generate favorable out comes as expected. many reasons such as, poor designing, less involvement in training need assessment and weak top management support and lack of post evaluation on implemented program.

Given these events and other factors it is clear that training and development and its impact on employee work related variables can be treated as a major human resources aspect which must be further explored and find alternative solutions to effectively dealing with this issue. Though the training \& development phenomenon and its implications on various perspectives have been comprehensively examined at international level, very less empirical research can be found in Sri Lankan context. In order to fill the existing gap in literature, the emphasis of this study was mainly on implications of training and development programs to work related variables with special reference to non staff employees at Naturub Accessories (Pvt) Ltd in Sri Lanka. Research problem that is addressed in this study was that "How non-staff employees respond to training and development programs in terms of work related outcomes of job satisfaction, productivity, and employee performance and employee turnover?"

\section{Literature review}

\section{Training and Development}

Over the year, training has become increasingly popular as a tool for enhancing employee managerial performance in organizations. The most widely used definition of training was suggested by Dressler (2003) who defined as "the process of teaching new employees the basic skills they need to perform their jobs. However, many experts distinguish between training with development. Stoner et al, (2000) argue that training refers to a process designed to maintain or improve current job performance while development program concerned on developing necessary skills of the employees for future work activities. This provides insight that development is a wider concept which is comprehensively focused on enhancing employees' knowledge, skills, and attitudes to perform their future task and responsibilities in an effective and efficient way.

\section{Types of training and development program}

Various types of training and development program are designed and implemented by the organizations. Basically training program can be categorized in to two pillars such as on the job and off the job training. Cannell (1997) defines on-the-job training as training
This is due to

that is planned and structured to takes place mainly at the normal workstation of the trainee. Further, under this program trainee spends a significant time with manager, supervisor, trainer or peer, colleague to learn a set of skills that have been specified in advance. Dressler (2000) argues that in many firms on the job training is the only training available. As far as the apparel industry which is surveyed company belongs to is concerned both on the job and off the job training methods are applied. Machine operators, cutters, helpers are basically supposed to involve in at least two weeks of training period. Depending upon the performance during the training period, management makes decision on transferring them in to actual production floor. However, when it comes to administrative or managerial level jobs several off the job training methods are capitalized along with the on the job training.

Cascio (2003) categorized basic form of on the job training and it includes job-instruction training, apprentice training, internships, job rotation and coaching. Most commonly used off the job training methods consist of lectures, special study, films, conference or discussion, case study, role playing, simulation and laboratory training.

\section{Consequences of training and development programs}

A number of studies have examined the consequences associated with training and development programs, and many of them found that most of the time favorable outcomes are inherited with it. Commonly examined outcome variables are job satisfaction, productivity and performance. In addition, in the present study intention to quit is also taken into account. According to Robins (2005), job satisfaction is defined as a collection of feelings that an individual holds toward his or her job". Wood, et al., (1998) extend the definition as the degree to which an individual feel positively or negatively about work. Moreover, Robins (2005) argue that satisfied employees are more productive than unsatisfied employees. Holton (1996) argues after involvement of the effective training program the motivational level of the employee will enhance thus the commitment to the organizational activities would be strengthened. Further, Desimone et al, (2002) point out organizations are required to offer continuous training program to ensure the lifelong employee satisfaction and commitment.

Robins (2005) define employee turnover as the voluntary and involuntary withdrawal from an organization. Fisher,et al., (2003) classified causes to quit into two layers: external and internal factors. 
External factors include the unemployment rate and employees' perceptions of the external job opportunities available to them. Internal factors are usually based on the employment attitudes or perceptions with respect to the current job. Kirkpatrick (1987) suggest that proper training program evaluation mechanism consist of four phases; such as reaction, learning, job behavior and results. Further Kirkpatrick (1987) argues once employee feels that continuous training opportunities are available in the organization, they may not make the decision on leaving the present employer.

Amstrong (1994) define performance as the multidimensional construct and it cover both behaviors and results. Snell and Bohlander (2007) contend that almost any employee needs some types of ongoing training to maintain effective performance with their job. Since the required knowledge, skills, competencies and attitudes are transferred through the training program, employees would be able to manage their routine work and adjust quickly to the contingency situations. Kirkpatrck (1987) point out that effective training and development program should enhance the employee performance. Improvement of the employee performance can be examined based on reducing scrap rates, and customers' complaints. Productivity of the employee and organization is an important element that is concerned in evaluating the success or failure of the training program. Warr et al, (1970) suggest output produced by the employees after the training should be enhanced. In addition the input output combination necessarily needs to be upgraded in favorably in turn increase the productivity level of the organization.

\section{Materials and Methods}

The objective of this research is to explore the impact of training and development programs towards work related variables of selected non staff employees who are involving with production process (worker level) at the Naturub Group of Companies. In the initial stage, a primary study was conducted to identify the sample. The Naturub Group of Companies consists of several subsidiaries and Naturub Accessories (Pvt) Ltd was selected as the research site among their major business cluster. The logic behind this selection was that the unit has reported the highest average investment cost on training and development per year. The Naturub Accessories (Pvt) Ltd is manufacturing garment accessories and consists of three production departments/sections. These three production departments were selected to collect the data due to the fact that a lot of workers are employed within those sections compared to others and larger product capacity is provided by Crochet, Braiding and Loom sections.

A structured questionnaire was used to collect the primary data from the sample of 110 employees in the above mentioned sections of the company. Data was collected using simple random sampling technique. The workable sample of employees consists of three sections; Crochet $(n=43)$, Braiding $(n=37)$, Loom $(n=30)$. The majority of the employees selected from Crochet as there were a lot of employees are deployed in that section. Data was collected from the 55 respondents just after three weeks from involving training program which was designed and implemented by the company particularly for worker level employees. The reason to carry out survey based on this circumstance was that employees are in position to evaluate the success of the training, certain time period after enrolling the training programs. In addition, at the same time data were collected from 45 employees those have not involved in that training program. Researcher gets the assistance from the Human resource manger to segregate the employees those who have participated and not participated in to the training program. As some workers was in the position that the inability of written skills, questionnaire was filled by the interviewer by obtaining ideas from employees. In addition, exploratory data gathered from HR Manager and Production Executives by using an unstructured style of interview. During the interview, the interviewer written down information and if needed, the Factory Manager of the company was contacted via telephone for further information. Questionnaire was divided in to two parts. Objective of the first part was to collect the general information while second part was based on employee attitudes on training and development programs. SPSS quantitative analytical tool was used to analyze the data where mean comparisons, Pearson correlation and hierarchical regression were run to prove the following hypothesis.

H1: Participation of training programs will increase the employees' job satisfaction, productivity and performance

H2: Participation of training programs will decrease the employees' intention to quit

Further, in order to test the internal consistency of the measuring instruments cronbach's alpha was calculated and the results are shown in the table 01 . 
Table 01: Cronbach's alpha values for variables

\begin{tabular}{lll}
\hline Variable & No of Items & Alpha \\
\hline Job Satisfaction (JS) & 06 & 0.67 \\
Intention to quit (IQ) & 05 & 0.72 \\
Productivity(PRO) & 05 & 0.65 \\
Performance(PER) & 05 & 0.58 \\
\hline
\end{tabular}

\section{Results and discussion}

Demographic variables was first analyzed and the sample consists of 71 female employees (64\%) and 39 male workers (36\%). As far as the frequency distribution of employees' age is concerned $71 \%$ of respondents belong to age category of 23 to 30 years

\section{Relationship between training program participation and work related variables:}

The Pearson correlation analysis was carried out to identify the direction and strength of the linear relationship between training program participation and four work related variables studied in the present study. Table 2 presents the results of the correlation analysis. Inspections of the bivariate correlation coefficients suggest that the hypothesis formulated in

Table 02: Correlation matrix the study were accepted. All the work related variables (Job Satisfaction: $r=0.582, n=110, p<0.05$ Productivity: $\mathrm{r}=0.432, \mathrm{n}=110, \mathrm{p}<0.05$ and Performance: $\mathrm{r}=0.641, \mathrm{n}=110, \mathrm{p}<0.05)$ reported positive correlation coefficients except turn over. This means that more the employee involvement in the training program higher the employees' job satisfaction, productivity and employee performance. However, Training program participation and employee turnover was negatively correlated $(\mathrm{r}=$ $0.611, \mathrm{n}=110, \mathrm{p}<0.05)$. This provides the insight that the knowledge, skills and attitudes gained through the training programs lead to minimize the employee intention to leave from the organization. As far as the statistical significance of the linear relationship is concerned as in the table 2 all work related variable have found the significant association between these variables.

\begin{tabular}{lll}
\hline Variable & Correlation coefficients & $\begin{array}{c}\text { Sig (2 Tailed) } \\
\mathbf{N}=\mathbf{1 1 0}\end{array}$ \\
\hline Job Satisfaction (JS) & $0.582^{* *}$ & 0.021 \\
Turnover (TO) & $-0.611^{* *}$ & 0.013 \\
Productivity(PRO) & $0.432^{* *}$ & 0.031 \\
Performance(PER) & $0.641^{* *}$ & 0.042 \\
\hline
\end{tabular}

$* * * \mathrm{p} \leq 0.01, * * \mathrm{p} \leq 0.05,{ }^{*} \mathrm{p} \leq 0.10$

\section{Hierarchical Regression Results}

In order to examine the predictive power of the training program participation on work related variables, hierarchical regression was carried out and results are shown in the table 03.As per the table 03, the introduction of not participating in the training program (step 01) does not show significant explained variance. However, inclusion of training program participation slightly increases the explained variance for all the dependant variable (work related variables) examined in the present study. This provides the insight that explanatory power of the training program participation is superior to the not involvement in the training program participation. With the incorporation of the training program participation in to the regression model increase the explained variance for job satisfaction by $19 \%$, turn over decision by $16 \%$, productivity by $12 \%$ and performance by $9 \%$. 
Table 03: Results of Hierarchical Regression

\begin{tabular}{llll}
\hline Dependant Variables & $\begin{array}{l}\text { Step 01 } \\
\text { Not involvement in the } \\
\text { Training program }\end{array}$ & $\begin{array}{l}\text { Step 02 } \\
\text { Adding participation of } \\
\text { the training program }\end{array}$ & $\begin{array}{l}\text { Increased in explained } \\
\text { variance }\end{array}$ \\
\hline $\begin{array}{l}\text { Job Satisfaction } \\
\text { R2 Adjusted }\end{array}$ & 0.042 & 0.234 & 0.192 \\
$\begin{array}{l}\text { F Value } \\
\text { Intention to quit }\end{array}$ & $7.581^{*}$ & $14.671^{* *}$ & \\
$\begin{array}{l}\text { R2 Adjusted } \\
\text { F Value }\end{array}$ & 0.055 & 0.216 & 0.161 \\
$\begin{array}{l}\text { Productivity } \\
\text { R2 Adjusted }\end{array}$ & 8.726 & $11.531^{* *}$ & \\
F Value & 0.038 & 0.161 & 0.123 \\
Performance & 5.231 & $13 . .351^{* *}$ & \\
R2 Adjusted & & & 0.092 \\
F Value & 0.029 & 0.121 & \\
\hline
\end{tabular}

\section{Conclusion}

The study conducted mainly with the objective of finding the relationship between employee involvement in training and development program and its impact on their work related variables. Across all four main variables tested namely job satisfaction, turnover, and productivity and performance researcher found that significance correlation between the variables. Moreover it was found that job Satisfaction, productivity and turnover were positively associated while turnover was negatively linked with training program participation. Based on this, researcher would like to conclude that the training program implemented by the company favorably influence on employee's work related

\section{References}

1. Hair, J., Babin, B., Anderson, R. \& Tatham, R., (2005). Multivarient Data Analysis. 6th ed.

2. Holton, E., (1996). The flawed four level evaluation model. Human Resource Development quarterly, Volume 7, pp. 5-21.

3. Kirpatrick, D., (1987). Training and development Handbook. McGraw Hill, Newyork.

4. Noe, A., (1986). Trainees' Attributes and Attitudes. Neglected influences on Training Effectiveness, Academy of Management Review 11, pp. 736-749. variables. However the research is limited in scope of time and the sample size. Thus this does not allow generalizing the results significantly for different organizational and cultural settings. Perhaps, the same conclusion cannot be drawn when it comes to the other subsidiaries in the Naturub group. On the other hand, during survey time period other variables were not controlled by the researcher. Thus, the favorable influence on work related variable sometime found due to other organizational stimulus like benefits program offered, entertainments facilities provided etc. Therefore it is essential to conduct the research on this aspect considering the all the other external influences.

5. Robbins, S., (2005). Organizational Behavior. Upper Saddle River, NJ:Prentice Hall.

6. Siben, I., (2007). Does training trigger turnover or not? The impact of formal training on graduates' job search behavior. Work employment society, Volume 21, pp. 397-416.

7. Snell, S. \& Bohlander, G., (2007). Human Resource Management. Baba Barkha Nath printers, Delhi.

8. Stoner, J., Freeman, R. \& Gilbert, D., n.d. Management. Prentice Hall, India. 
9. Warr, P., Bird, M. \& Rackman, N., (1970).

Evaluation of management training. Gower press, London. 